\title{
The regeneration status of the endangered Acer opalus subsp. granatense throughout its geographical distribution in the Iberian Peninsula
}

\author{
Lorena Gómez-Aparicio *, Regino Zamora, Jose M. Gómez \\ Departmento Biología Animal y Ecología, Facultad de Ciencias, Universidad de Granada, Grupo de Ecología Terrestre, E-18071 Granada, Spain
}

\begin{abstract}
Acer opalus subsp. granatense is an endemic endangered tree with a wide but fragmented distribution in the Mediterranean mountains. The persistence of its small populations often depends on just a few adults, and consequently is highly vulnerable to factors limiting recruitment. In this paper, we examined the regeneration status of this maple in 16 populations throughout its whole geographical distribution in the Iberian Peninsula. Age and size structures were analysed as indicators of the viability of the species. Additionally, we studied the effects of herbivory by ungulates and the role of shrubs as nurse plants in maple regeneration dynamic. Our results show that A. opalus subsp. granatense has active recruitment throughout its range in the Iberian Peninsula. Shrubs served as the main microsites for recruitment, not only for early establishment but also for long-term survival. However, ungulates heavily damaged maple saplings in all locations and microhabitats. A direct consequence of herbivory is the uncoupling of age and size structures, saplings becoming older but not higher, possibly affecting population turnover in the long term. We suggest that the conservation of the small populations of Acer opalus subsp. granatense heavily depends on the control of herbivory pressure throughout the maple distribution area.
\end{abstract}

Keywords: Acer opalus subsp. granatense; Age and size structures; Herbivory by ungulates; Iberian Peninsula; Mediterranean mountains; Population regeneration; Nurse plants

\section{Introduction}

The mountain areas of the Mediterranean Basin contain the highest plant diversity in Europe, due to both historical and biological reasons (Cowling et al., 1996; Blanca et al., 1998; Blondel and Aronson, 1999; Grove and Rackham, 2001). In this diverse scenario, some species have a wide but highly scattered distribution, consisting of many small montane populations. These fragmented distributions are in many cases linked to the role of mountain habitats as refuges during glacial-interglacial cycles (Bennett et al., 1991; Vogel et al., 1999). However, human intervention has also exacerbated fragmentation processes by cutting, fires and overgrazing, with the native forests being reduced to isolated patches immersed in a matrix of humanized landscapes. Specifically, the increase of both wild and domestic livestock over thousands of years in Mediterranean habitats has severely affected the regeneration ability of tree populations and the resulting forest species composition, due to the selective consumption of seedlings, saplings and resprouts (Noy-Meir et al., 1989; Dubost, 1998).

Species with wide geographic distribution but small population sizes have been considered to constitute a specific category of rarity requiring a particular approach for conservation (Rabinowitz et al., 1986). To assure the persistence of these species at a regional scale is specially challenging, since threatens acting at a local scale might destroy whole populations, thereby reducing the plant's geographic distribution. Because factors limiting plant recruitment are highly heterogeneous in space and time (Clark et al., 1999), the conservation of 
these rare species requires broad-scale studies that analyse population viability not only in particular localities, but in a high number of them covering the diversity of ecological settings faced by the species (Schemske et al., 1994).

The Iberian-Mauritanian endemic Acer opalus subsp. granatense (Boiss.) Font Quer\&Rothm. represents in the Iberian Peninsula a clear example of species with a distribution composed of small patches scattered along several mountains (López-Gónzalez, 1994). Its populations usually appear on north-facing slopes, shady ravines or areas near riverbanks, where Mediterranean summer drought is partially ameliorated by special topographic or soil conditions (Costa et al., 1998). It has been catalogued as Vulnerable by the IUCN (2000), and therefore included in the recent Red List of Threatened Vascular Plants of Andalusia (Blanca et al., 2000). Although little information is available about natural regeneration of maple populations, pilot studies have shown that saplings are intensively damaged by ungulates in mountains of southeastern Spain (Hódar et al., 1998, Zamora et al., 1999). In fact, maple recruits usually appear surrounded by shrubs (Gómez et al., 2001a), which suggests that saplings could benefit from the protective role of nurse shrubs, as have been proposed for other woody species in Mediterranean areas (see García et al., 2000 for Taxus baccatta).

The present work was performed to analyse the population viability of $A$. opalus subsp. granatense throughout the geographical distribution of the species in the Iberian Peninsula. With this aim, we investigated the age and size structure of maple populations. This information, reflecting the pattern and periodicity of recruitment, enabled us to reconstruct regeneration dynamics in the past and thereby predict the future viability of the species (Ogden, 1985; Andrzejczyk and Brzeziecki, 1995; Primack, 1995; García et al., 1999). Unbalanced age or size structures would indicate the existence of factors hampering transitions between classes (Sano, 1997). Based on previous studies, we focus on the analysis of herbivory by ungulates as a main factor potentially affecting maple population structures. Both demographic structures and herbivory were analysed using two different approaches. First, we visited a high number of populations in order to observe whether the effects of ungulates are consistent throughout the maple distribution area or if, conversely, they are only relevant at particular locations. Second, we compare demographic structures and spatial distribution of recruits in populations located inside and outside experimental exclosures. This experimental approach allows us to evaluate the magnitude of the effect of browsing ungulates on regeneration, as well as to analyse their impact in spatial patterns of recruitment and the role of nurse shrubs in relation to herbivore damage.

\section{Methods and study area}

\subsection{Population sampling along a latitudinal gradient}

During summer and autumn 2002, we visited 16 populations of $A$. opalus subsp. granatense located at medium and high altitudes (1000-2000 m) throughout the geographical distribution area of the species in the Iberian Peninsula, covering a latitudinal gradient from $36^{\circ} \mathrm{N}$ to $40^{\circ} \mathrm{N}$ (Table 1, Fig. 1). All populations were isolated from other maple species such as Acer monspessulanum and A. opalus subsp. opalus, in order to avoid hybridization problems. In each location, individuals were sampled using $25 \mathrm{~m}$ transects $(n=10)$ haphazardly distributed in a representative area of the population 1-2 ha in size (Bullock, 1996). The width of the transect was $2 \mathrm{~m}$ for saplings and $10 \mathrm{~m}$ for adults (50 $\mathrm{m}^{2}$ for saplings and $250 \mathrm{~m}^{2}$ for adults). For each sapling, we recorded:

1. Total height, in $\mathrm{cm}$. Size structures were established grouping saplings in 6 categories of $20 \mathrm{~cm}$, up to a height above $100 \mathrm{~cm}$.

2. Age, counting growth scars on the main stem (see Taylor and Aarssen, 1989 and Boerner and Brinkman, 1996 for a similar method with Acer saccharum). We counted scars until an approximate age of 15-16 years (from which age estimation becomes increasingly difficult). Saplings were grouped in 5 age classes following a geometrical progression: 2 years, 3-4 years, 5-8 years, 9-16 years and more than 16 years.

3. Accumulated herbivore damage, estimated as the percentage of browsed shoots (in the current and in previous years) in relation to the total number of shoots. These data were used to calculate two complementary herbivory indexes per population (Zamora et al., 2001): risk of herbivory (estimated as the percentage of saplings browsed) and accumulated damage intensity (estimated as the percentage of browsed shoots per plant in relation to the total number of shoots).

4. Microhabitat, considering four main categories: (1) Maple microsite, under the canopy of adult maples; (2) Canopy microsite, under the canopy of non-conspecific tree adults together with shrubs $1.5-2 \mathrm{~m}$ in height; (3) Shrub microsite; (4) Open microsite, distinguishing between rocky, stony (with abundant loose stones) and soil (with a deep soil and scarce stones).

At every $2 \mathrm{~m}^{2}$ in each transect we also recorded cover percentages of the different species and/or substrate types (in the case of bare ground), in order to explore the relationship between maple spatial distribution and habitat structure across populations. The wide range of covers found was grouped in the same four microhabitats described above (Maple, Canopy, Shrub and Open). Additionally, for each population, we recorded: (1) geographic characteristics (latitude, altitude, slope); (2) 

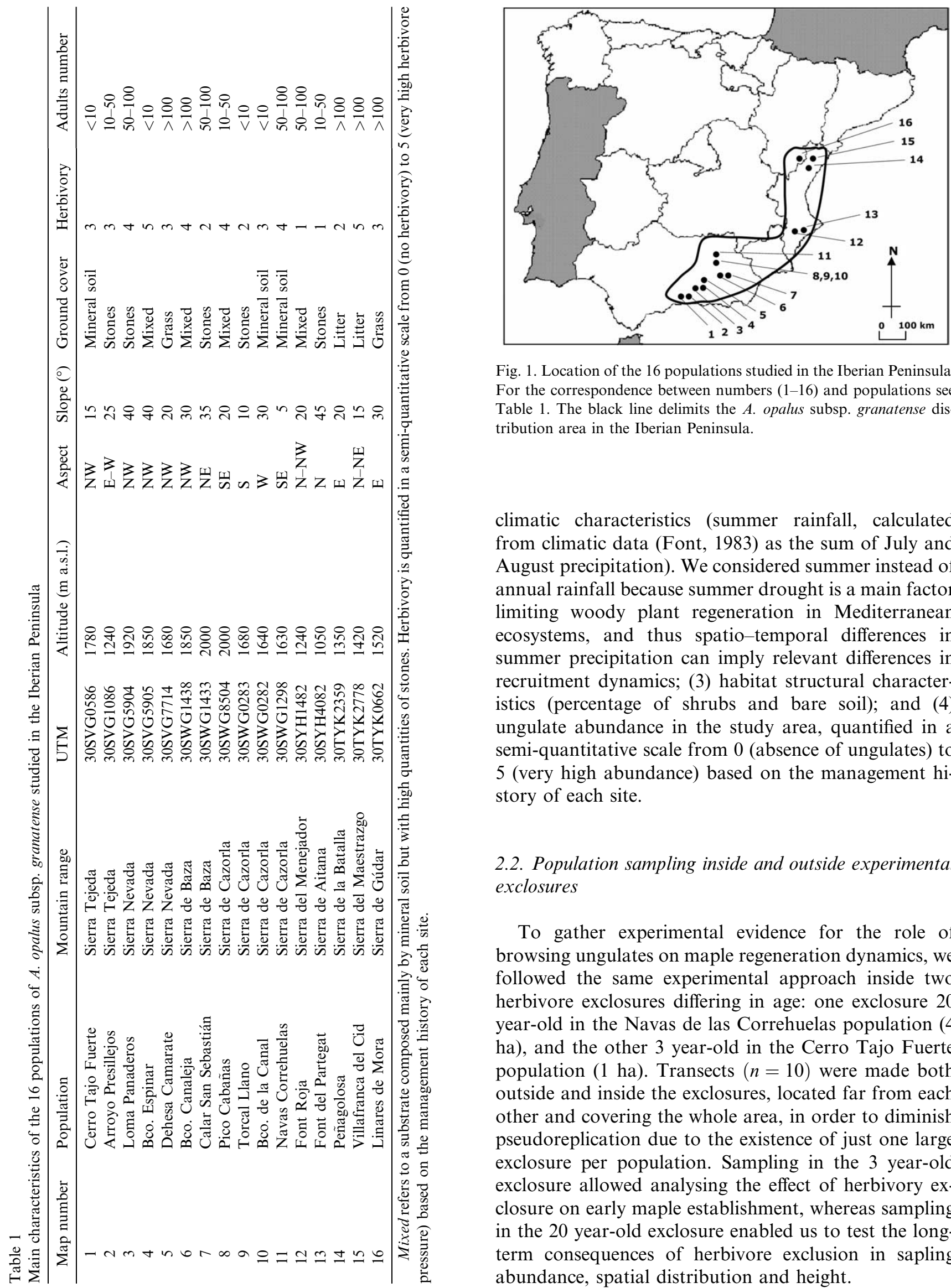

Fig. 1. Location of the 16 populations studied in the Iberian Peninsula. For the correspondence between numbers (1-16) and populations see Table 1 . The black line delimits the A. opalus subsp. granatense distribution area in the Iberian Peninsula.

climatic characteristics (summer rainfall, calculated from climatic data (Font, 1983) as the sum of July and August precipitation). We considered summer instead of annual rainfall because summer drought is a main factor limiting woody plant regeneration in Mediterranean ecosystems, and thus spatio-temporal differences in summer precipitation can imply relevant differences in recruitment dynamics; (3) habitat structural characteristics (percentage of shrubs and bare soil); and (4) ungulate abundance in the study area, quantified in a semi-quantitative scale from 0 (absence of ungulates) to 5 (very high abundance) based on the management history of each site.

\subsection{Population sampling inside and outside experimental exclosures}

To gather experimental evidence for the role of browsing ungulates on maple regeneration dynamics, we followed the same experimental approach inside two herbivore exclosures differing in age: one exclosure 20 year-old in the Navas de las Correhuelas population (4 ha), and the other 3 year-old in the Cerro Tajo Fuerte population $(1 \mathrm{ha})$. Transects $(n=10)$ were made both outside and inside the exclosures, located far from each other and covering the whole area, in order to diminish pseudoreplication due to the existence of just one large exclosure per population. Sampling in the 3 year-old exclosure allowed analysing the effect of herbivory exclosure on early maple establishment, whereas sampling in the 20 year-old exclosure enabled us to test the longterm consequences of herbivore exclusion in sapling abundance, spatial distribution and height. 


\subsection{Data analysis}

Between-population differences in adult and sapling density, and age and size structure, were analysed using Generalized Linear Mixed Models (Proc MIXED, SAS, 2002), population being introduced as a random variable. Adult and sapling density were fitting to Poisson distributions with Log as link function, whereas age and size classes were fitting to multinomial distributions with Logit as link function. For the analysis of the effect of exclosures on sapling density, adult density was introduced as a covariate, in order to control potential differences in recruit abundance due to different seedsource densities inside and outside the exclosures. Spearman rank correlations were performed to explore the relation between sapling density and the coarsegrain characteristics recorded for each population.

Population structures were fitted to inverse J-shaped curves $\left(y=a \mathrm{e}^{-b x}\right)$, the shaped distribution of natural tree populations with abundant regeneration (Condit et al., 1998). In this equation, $y$ represents the sapling percentage, $x$ the age/size class, and $a$ and $b$ are the intercept and the slope of the curve, respectively. To fit our empirical data to the theoretical J-shaped curve, a non-linear fitting with an iterative Gauss-Newton method was used (SAS, 2002). This method searches for the least-square estimates of the parameter values, and offers a goodness of fit between the theoretical and the empirical curves.

Differences between populations in the sapling distribution across microhabitats were analysed using Generalized Logit Models (Proc CATMOD, SAS, 2002) using maximum likelihood estimations (Stokes et al., 1995). To determine whether spatial patterns of recruitment followed a random distribution, we compared by using $\chi^{2}$ tests for each population the observed distribution of saplings across microhabitats with the expected distribution considering abundance proportional to the microhabitat cover. The same approach was used to explore variation with age of sapling spatial patterns, $\chi^{2}$ tests being conducted for each age class separately. However, because in many populations there were not saplings in every combination of age class and microhabitat, we pooled the total number of saplings in the 16 populations.

The risk of herbivory was analysed using Generalized Logit Models (Proc CATMOD, SAS, 2002), and the damage intensity using ANOVAs (Proc GLM, SAS, 2002). In both cases, population was introduced as a random factor, and microhabitat and age as fixed factors. Microhabitat was not nested in population because we considered it relevant to obtain general conclusions related to microhabitat quality for recruitment. Damage data were previously arc-sin transformed to increase homogeneity and heterocedasticity (Zar, 1996). We used Type III sum of squares due to the unbalanced nature of the data. To control for the Type 1 Error produced by multiple comparisons, we used the sequential Bonferroni technique (Rice, 1989). Since seedling height should increase as an exponential function of age, we analysed the effect of herbivory in sapling growth rate by determining, for browsed and non-browsed saplings, the least squares best fit regression line using the equation height $=a \mathrm{e}^{b * a g e}$. This equation takes the form of a straight line when plotted semi-logarithmically, with the growth rate (b) being the slope of the resulting regression line (Leopold and Kriedemann, 1975). The same analysis was carried out with saplings inside and outside the 20 year-old exclosure in order to examine the longterm effect of ungulate exclusion on growth rates. To contrast the slopes we used ANCOVAs (Proc GLM, SAS, 2002) with interaction terms, introducing herbivory and age as independent variables.

\section{Results}

\subsection{Habitat structure}

The 16 populations differed markedly in their habitat structure. The most variable characteristic was the shrub cover, which varied from around $80 \%$ in the southwesternmost population to less than $2 \%$ in the dense forests of the northernmost edge (average cover $21.7 \pm 4.9 \%$ ). Populations with the highest percentage of shrubs also had the lowest cover of conspecific and nonconspecific trees. Maple and Canopy microhabitats represented on average $16.9 \pm 3.1 \%$ and $19.8 \pm 3.3 \%$ (respectively) of the habitat structure of the populations $(n=16)$. Finally, Open microhabitat varied among populations not only in quantity but also in quality, with populations composed mainly of stony and rocky substrate (up to $81.6 \%$ of the habitat structure) while in others bare ground was mostly deep soil (average cover $45.2 \pm 3.9 \%$ ).

\subsection{Population demographic structure}

Sapling density was highly variable between populations $\left(L-R \chi^{2}=4206.12, \mathrm{df}=15, p<0.0001\right)$ with values ranging from 1 to 219.6 juveniles $/ \mathrm{m}^{2}$. Although there were also significant between-population differences in adult density $\left(L-R \chi^{2}=133.86, \mathrm{df}=15, p<0.0001\right)$, the variation range was much lower than for saplings (from 0.2 to 1.7 adults $/ \mathrm{m}^{2}$ ). In fact, sapling density did not significantly correlate with total adult density $\left(r_{\mathrm{s}}=0.11\right.$, $p=0.26$, Spearman correlation). From among the characteristics recorded per population, sapling density was only significantly correlated with the percentage of bare soil $\left(r_{\mathrm{s}}=-0.67, p<0.01\right)$. Highly significant between-population differences were found for age $(L-R$ $\left.\chi^{2}=1063.97, \mathrm{df}=75, p<0.0001\right)$ and size structures 


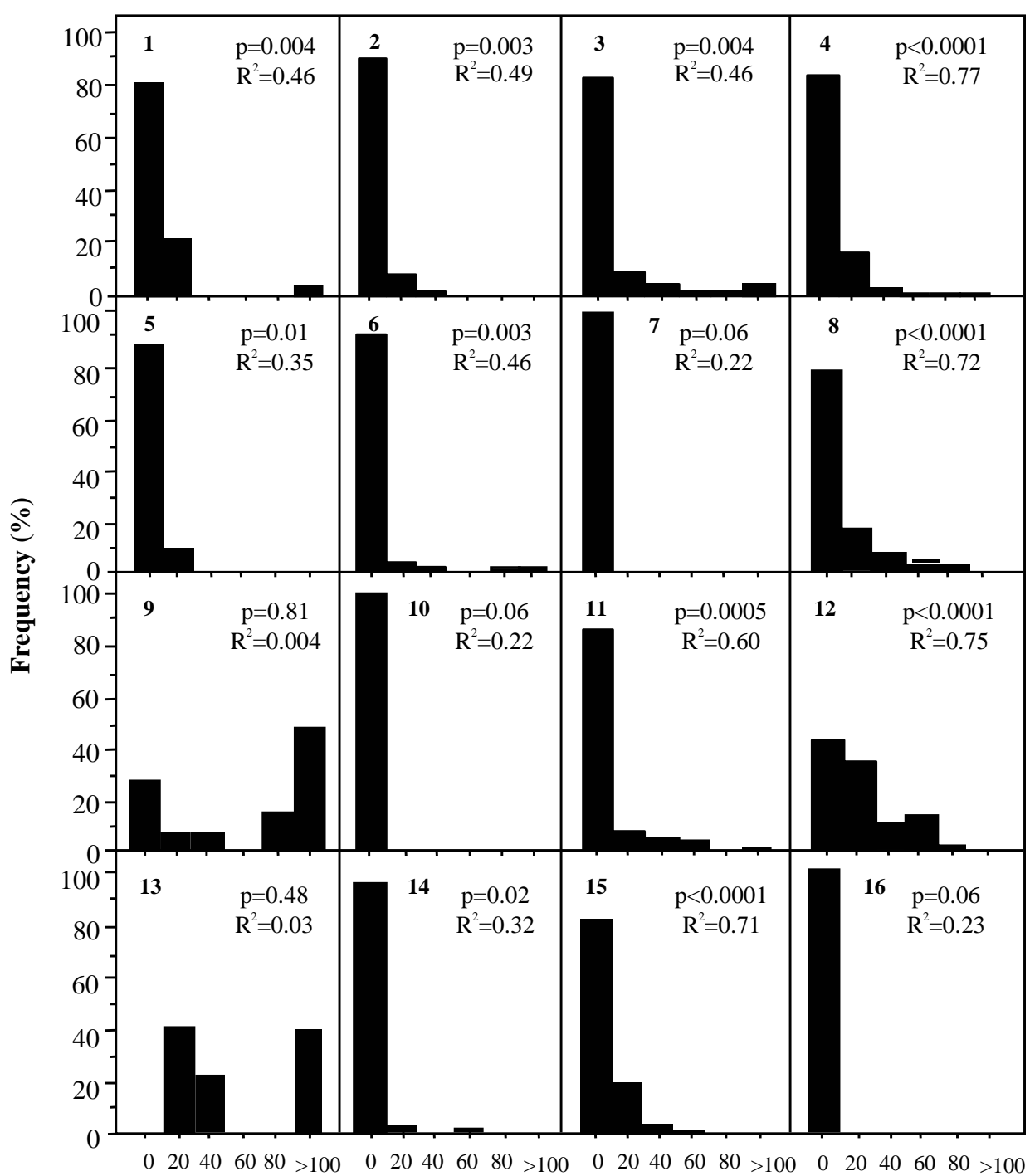

Size $\operatorname{class}(\mathbf{c m})$

Fig. 2. Size structures of the 16 maple population studied. $p$ values show the significance of the fitting to inverse J-shaped curves, whereas $R^{2}$ indicates the percentage of the dependent variable explained by the theoretical model (see Section 2 for further details). For the correspondence between numbers (1-16) and populations see Table 1.

$\left(L-R \chi^{2}=294.64, \mathrm{df}=75, p<0.0001\right)$. The fitting of age structures to inverse $\mathrm{J}$-shaped curves was significant for only two populations (Navas de las Correhuelas and Dehesa del Camarate, $r^{2}=0.79, p<0.01$ for both cases; data not shown). However, size structures significantly fitted in 11 of the 16 cases (Fig. 2).

\subsection{Spatial pattern of sapling recruitment}

There were significant between-population differences in the spatial pattern of sapling recruitment $\left(L-R \chi^{2}=1401.81, \mathrm{df}=45, p<0.0001\right)$. Contingency analyses comparing observed and expected sapling distribution per microhabitat were significant in 14 out of the 16 populations (Table 2). In 13 of these 14 populations, the number of saplings in open microsites was lower than expected, whereas in 10 populations the abundance of saplings under shrubs was higher than expected. Association with non-conespecific trees was for most populations lower than expected, whereas the association with maples depended heavily on the population considered. When these comparisons where made for each age class, we found for all of them significant differences between the observed and expected sapling distribution across microhabitats $(p<$ 0.001 for classes 1 and $2, p<0.0001$ for classes $3-5, \chi^{2}$ analyses). The association between saplings and tree cover (both Canopy and Maple) decreased with age (Fig. 3). On the contrary, the pattern of higher association than expected with shrubs, and lower than 
Table 2

Summary of the contingency analysis $\left(\chi^{2}\right)$ testing the differences between the observed and expected sapling percentages in each microhabitat

\begin{tabular}{|c|c|c|c|c|c|c|c|c|c|c|}
\hline \multirow{3}{*}{$\begin{array}{l}\text { Population } \\
\text { Arroyo Presillejos }\end{array}$} & \multirow{3}{*}{$\begin{array}{l}\chi^{2} \\
68.47\end{array}$} & \multirow{3}{*}{$\begin{array}{l}p \\
<0.0001\end{array}$} & \multicolumn{8}{|c|}{$\%$ Observed (expected) } \\
\hline & & & \multicolumn{2}{|l|}{$\overline{\text { Shrub }}$} & \multicolumn{2}{|c|}{ Open } & \multicolumn{2}{|l|}{ Maple } & \multicolumn{2}{|c|}{ Canopy } \\
\hline & & & 5 & {$[+]$} & 23 & {$[+]$} & 69 & {$[-]$} & 3 & {$[+]$} \\
\hline Cerro Tajo Fuerte & 14.61 & 0.0001 & 97 & {$[-]$} & 3 & {$[+]$} & 0 & & 0 & \\
\hline Loma Panaderos & 22.85 & $<0.0001$ & 55 & {$[-]$} & 32 & {$[+]$} & 11 & {$[+]$} & 1 & {$[+]$} \\
\hline Bco. Espinar & 23.65 & $<0.0001$ & 74 & {$[-]$} & 11 & {$[+]$} & 9 & {$[-]$} & 6 & {$[+]$} \\
\hline Dehesa Camarate & 81.18 & $<0.0001$ & 91 & {$[-]$} & 4 & {$[+]$} & 4 & {$[+]$} & 0 & \\
\hline Bco. Canaleja & 21.74 & $<0.0001$ & 11 & {$[+]$} & 27 & {$[+]$} & 54 & {$[-]$} & 8 & {$[+]$} \\
\hline Calar S. Sebastián & 77.98 & $<0.0001$ & 14 & {$[+]$} & 1 & {$[+]$} & 29 & {$[-]$} & 57 & {$[-]$} \\
\hline Cabañas & 29.40 & $<0.0001$ & 64 & {$[-]$} & 8 & {$[+]$} & 11 & {$[-]$} & 16 & {$[+]$} \\
\hline Torcal Llano & 27.74 & $<0.0001$ & 33 & {$[-]$} & 67 & {$[-]$} & 0 & & 0 & \\
\hline Bco. de la Canal & 13.39 & 0.004 & 6 & {$[+]$} & 23 & {$[+]$} & 21 & {$[-]$} & 50 & {$[-]$} \\
\hline Navas Correhuelas & 39.14 & $<0.0001$ & 30 & {$[-]$} & 19 & {$[+]$} & 26 & {$[-]$} & 25 & {$[-]$} \\
\hline Font Roja & 11.72 & 0.008 & 45 & {$[-]$} & 45 & {$[+]$} & 2 & {$[+]$} & 8 & {$[-]$} \\
\hline Font del Partegat & 28.41 & $<0.0001$ & 60 & {$[-]$} & 40 & {$[+]$} & 0 & & 0 & \\
\hline Peñagolosa & 6.34 & 0.096 & 1 & & 0 & & 9 & & 90 & \\
\hline Villafranca del Cid & 0.16 & 0.984 & 1 & & 12 & & 60 & & 27 & \\
\hline Linares de Mora & 83.59 & $<0.0001$ & 13 & {$[-]$} & 10 & {$[+]$} & 70 & {$[-]$} & 7 & {$[+]$} \\
\hline Total & 23.19 & $<0.0001$ & 28 & {$[-]$} & 16 & {$[+]$} & 35 & {$[-]$} & 21 & {$[+]$} \\
\hline
\end{tabular}

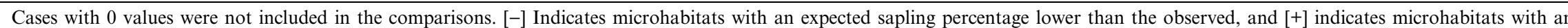
expected sapling percentage higher than the observed. 


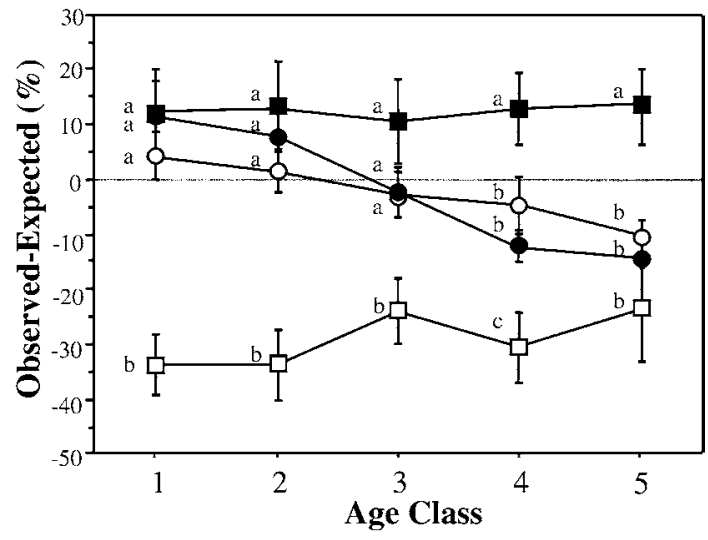

Fig. 3. Variation with age in the difference between observed and expected sapling abundance in each microhabitat (mean $\pm 1 \mathrm{SE}, n=16$ ). Positive and negative percentages signify the existence of more/less saplings than expected if their abundance were proportional to the microhabitat cover. Age classes are: $1=2$ years; $2=3-4$ years; $3=5-8$ years; $4=9-16$ years; $5>16$ years. Different letters indicate significant differences between microhabitats for the same age class according to one-way ANOVAs (after Bonferroni correction at $\alpha<0.05$ ). Microhabitats are: Maple (O), Canopy $(\bigcirc)$, Shrub (ם) and Open $(\square)$.

expected with open microsites, persisted across the five age classes (Fig. 3).

\subsection{Herbivore damage by ungulates}

All factors significantly affected the risk of herbivory and intensity of damage (Table 3). Between populations, the risk of herbivory varied between $0 \%$ and $90.7 \%$, and the intensity of damage between $16.6 \%$ and $92.5 \%$. Risk of herbivory increased significantly with age (Fig. 4). Damage intensity, on the contrary, showed a decreased from class 1 to 2 , and then an increase from class 3 to 5 . However, this result is presumably influenced by the fact
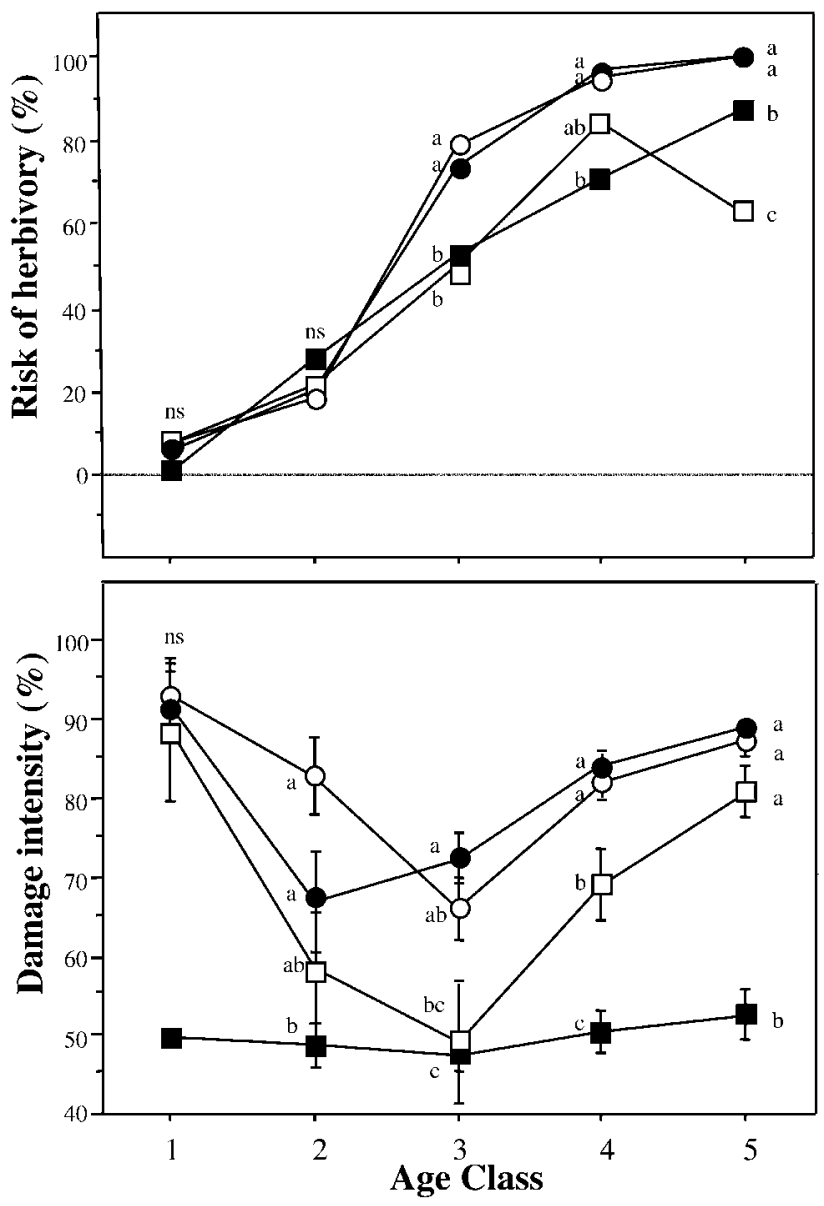

Fig. 4. Variation with age in the risk of herbivory (\%) and the damage intensity $(\%)$ suffered by maple saplings in different microhabitats (mean $\pm 1 \mathrm{SE}, n=16$ ). Different letters indicate significant differences between microhabitats for the same age class (after Bonferroni correction at $\alpha<0.05$ ) according to pairwise $\chi^{2}$ tests (risk of herbivory) or one-way ANOVAs (damage intensity). Microhabitats are: Maple ( ), Canopy (O), Shrub (ם) and Open ( $\square)$.

Table 3

Summary of the contingency analysis $\left(\chi^{2}\right)$ for the risk of herbivory, and the general linear model ANOVA $(F)$ for damage intensity testing the effect of population, microhabitat and age class

\begin{tabular}{|c|c|c|c|c|}
\hline Variable & Factors & $\mathrm{df}$ & $\chi^{2}$ & $p$ \\
\hline \multirow[t]{6}{*}{ Risk of herbivory ${ }^{a}$} & Population [random] & 15 & 257.75 & $<0.0001$ \\
\hline & Microhabitat & 3 & 13.39 & 0.0039 \\
\hline & Age class & 4 & 483.05 & $<0.0001$ \\
\hline & Microhabitat $\times$ age class & 12 & 22.11 & 0.0363 \\
\hline & Error & 1570 & & \\
\hline & & $\mathrm{gl}$ & $F$ & $p$ \\
\hline \multirow[t]{5}{*}{ Damage intensity ${ }^{\mathrm{b}}$} & Population [random] & 13 & 7.33 & $<0.0001$ \\
\hline & Microhabitat & 3 & 5.08 & 0.0018 \\
\hline & Age class & 4 & 14.10 & $<0.0001$ \\
\hline & Microhabitat $\times$ age class & 12 & 2.18 & 0.0112 \\
\hline & Error & 584 & & \\
\hline
\end{tabular}

Those interactions generating singularity in the variance-covariance matrix and lost dfs were eliminated.

${ }^{\mathrm{a}}$ Whole model for risk of herbivory: $\chi^{2}=1172.25, p<0.0001, R^{2}=0.57$.

${ }^{\mathrm{b}}$ Whole model for damage intensity: $F_{32,584}=19.87, p<0.0001, R^{2}=0.52$. 
Summary of the ANCOVA analyses to compare the age-height regression slopes between (1) damaged and non-damaged saplings in the 16 populations sampled throughout the Iberian Peninsula, and (2) saplings inside and outside the 20 year-old exclosure located in the Navas de las Correhuelas population

\begin{tabular}{|c|c|c|c|c|c|}
\hline & Factors & $\mathrm{df}$ & SS & $F$ & $p$ \\
\hline \multirow[t]{4}{*}{16 Populations $^{\mathrm{a}}$} & Herbivory & 1 & 24.35 & 103.41 & $<0.0001$ \\
\hline & Age & 1 & 435.03 & 1847.53 & $<0.0001$ \\
\hline & Herbivory $\times$ age & 1 & 47.69 & 202.53 & $<0.0001$ \\
\hline & Error & 1588 & 373.92 & & \\
\hline \multirow[t]{4}{*}{20 Year-old exclosure $^{b}$} & Exclosure & 1 & 0.40 & 6.44 & 0.0123 \\
\hline & Age & 1 & 20.96 & 335.31 & $<0.0001$ \\
\hline & Exclosure $\times$ age & 1 & 0.58 & 9.24 & 0.0028 \\
\hline & Error & 137 & 8.56 & & \\
\hline
\end{tabular}

${ }^{\mathrm{a}}$ Whole model for the 16 populations: $F_{3,1588}=942.86, p<0.0001, R^{2}=0.64$.

${ }^{\mathrm{b}}$ Whole model for the 20 year-old exclosure: $F_{3,137}=121.55, p<0.0001, R^{2}=0.73$.

that young saplings have just a few shoots (usually 1 or 2 ), and consequently they usually suffered damage intensity equal to $50 \%$ or higher. Differences between microhabitats in herbivory varied depending on age (significant age class $\times$ microhabitat interaction both for risk of herbivory and damage intensity; Table 3). Whereas no differences between microhabitats were found in the risk of herbivory for age classes 1 and 2, for classes 3-5 risk was highest in Maple and Canopy microhabitats (Fig. 4). Saplings in Shrub and Open microsites showed similar risk of herbivory. Damage intensity was lowest under shrubs, the difference in relation to the other microsites increasing with sapling age (Fig. 4). Herbivory significantly affected the sapling growth rate (significant herbivory $\times$ age interaction; Table 4), unbrowsed saplings growing faster than browsed saplings (height $=1.271 \mathrm{e}^{0.152 \text { age }}$ versus height $=$ $1.738 \mathrm{e}^{0.073 a g e}$, respectively).

\subsection{Effects of exclosures on sapling abundance, spatial distribution and growth rate}

Exclosures did not affect sapling density, either over the short term $\left(L-R \chi^{2}=1.44, \mathrm{df}=1, p=0.23\right.$, $)$ or over the long term $\left(L-R \chi^{2}=0.62\right.$, df $\left.=1, p=0.43\right)$. Likewise, none of the exclosures affected the spatial pattern of sapling recruitment $\left(L-R \chi^{2}=6.54, \mathrm{df}=3\right.$, $p=0.09$ for the 20 year-old exclosure, $L-R \chi^{2}=0.02$, $\mathrm{df}=3, p=0.88$ for the 3 year-old exclosure). The main long-term effect of the exclosure was on size structure $\left(L-R \chi^{2}=34.6, \mathrm{df}=5, p<0.0001\right.$; Fig. 5). Whereas outside the 20 year-old exclosure no sapling surpassed $80 \mathrm{~cm}$, inside the exclosure about $20 \%$ of the saplings exceeded $100 \mathrm{~cm}$ in height (Fig. 5). Additionally, exclusion from ungulates significantly affected sapling growth rate, with saplings inside the exclosure growing faster than saplings outside the exclosure (height $=0.412 \mathrm{e}^{0.091 \text { age }}$ versus height $=$ $0.594 \mathrm{e}^{0.051 \text { age }}$, respectively; Table 4$)$.

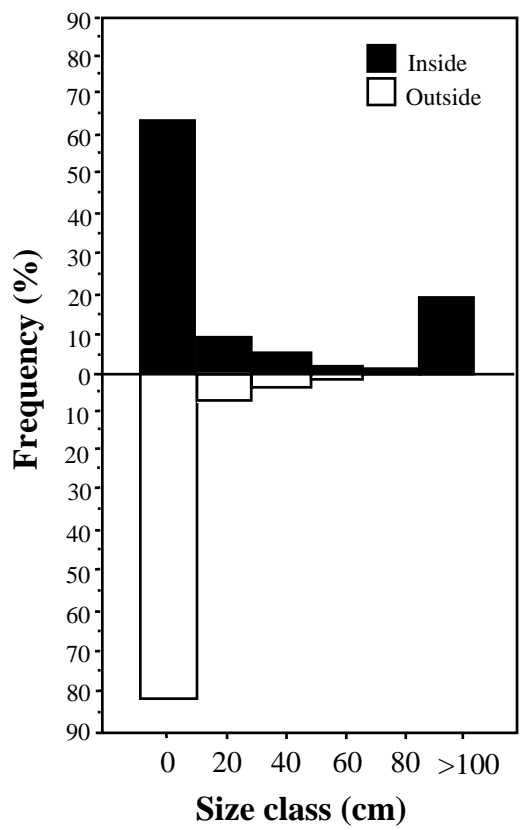

Fig. 5. Size structures of maple populations inside and outside the 20 year-old exclosure.

\section{Discussion}

Results have shown that $A$. opalus subsp. granatense has a general pattern of active recruitment under natural conditions, sapling abundance being invariably much higher than adult abundance. Moreover, this pattern applied to the entire distribution area in the Iberian Peninsula regardless of the type of population. In fact, geographic and climatic characteristics examined at the regional level did not adequately predict sapling abundance. This lack of correlation could arise from the fact that maple populations usually appeared in special locations such as stream beds, shady ravines or stony piles in the high mountains, where microclimatic conditions are to some extent different (more humid and shady) 
from the general climate. These settings would allow maple populations to transcend climatic variation imposed by latitudinal or altitudinal gradients, their regeneration dynamics probably being more related to within-population heterogeneity than to constraints imposed at a larger scale (Gray and Spies, 1997).

\subsection{Spatial distribution of saplings within populations}

Sapling recruitment did not show a random spatial distribution, since most populations showed significant differences between the observed and expected sapling distribution across microhabitats. Only in the northernmost populations was recruitment distribution proportional to microhabitat cover. Taking into account the high homogeneity of these populations at the microhabitat scale ( $>90 \%$ tree cover), it is likely that their spatial patterns of regeneration respond to environmental variation at a finer scale (e.g., different substrates such as tip-up mounds, rooting wood, mineral soil etc., or distribution of canopy gaps), in a similar way as has been widely reported for temperate and boreal forests (Smallidge and Leopold, 1994; Simard et al., 1998).

The greatest sapling percentages occurred under adult maples and shrubs, the role of shrubs as main regeneration sites becoming increasingly relevant in a northto-south latitudinal gradient. As dense woodlands are replaced by shrublands with just some isolated adult maples, the percentage of recruits associated with shrubs rose significantly, the recruitment in open areas or under maples being almost nil. This close spatial association between maple saplings and shrubs indirectly suggests strong nurse-plant relationships (Callaway, 1995). On the other hand, open spaces were the worst microsites for recruitment all along the geographical gradient explored. In fact, the only abiotic characteristic that significantly explained sapling abundance was the percentage of open area in the habitat structure of the population, implying that maple recruitment could be at least partially limited by adequate microsites for recruitment (Nathan and Muller-Landau, 2000). Not surprisingly, the habitat structure of the only population lacking saplings in the lower age class was largely bare soil with loose stones $(84.7 \%)$, a substrate that could cause a slow and random recruitment dynamic due to extremely high probability of seedling death through physical damage.

Spatial patterns of sapling recruitment showed high variation with age. The observed sapling abundance in Maple and Canopy varied from higher than expected in age classes 1 and 2 to lower than expected in higher classes. This shift in spatial patterns suggests the increasing magnitude of competitive asymmetrical interactions between saplings (the weaker competitors) and adults (the stronger competitors) with age, probably due to overlaps in the use of resources (Winn, 1985; Lorimer et al., 1994; Buckley et al., 1998). On the contrary, relationships between expected and observed sapling abundance in Shrub and Open microhabitats remained constant across age classes, with shrubs consistently presenting more and open microsites fewer saplings than expected. Thus, shrubs were not only one of the most important microhabitats for recruitment in terms of sapling number but, weighted by age, their quality as regeneration sites increased, representing the microsites where maples have a higher long-term probability of surviving and growing. This high microhabitat dependence, together with the fact that regional variables did not adequately explain maple recruitment, supports the idea that microsite heterogeneity, or heterogeneity at the seedling/sapling scale, has an overwhelming impact on maple regeneration dynamics beyond larger-scale environmental gradients (see also Rooney and Waller, 1998).

\subsection{Effects of herbivores on sapling spatial distribution and growth}

Results from the present study show that maple saplings suffer intense damage by domestic and wild ungulates throughout its whole distribution area. Despite the wide range of conditions explored and the high spatial variability that characterized herbivory (Zamora et al., 1999), average herbivory did not fall below the $60 \%$ for risk and the $50 \%$ for damage intensity in any population, with both variables reaching $90 \%$. Moreover, there were no safe microsites for maples to escape from ungulates. Indeed, risk of herbivory was similarly high in shrubs and in open spaces, whereas damage intensity, although lower in shrubs, never diminished below 50\% and consistently affected the leader shoot (author's pers. obs.). Thus, it appears that maple saplings are always severely browsed independently of the ecological context of the individuals, both at the local and at the microhabitat scale (see Morrison et al., 2002 for same results with Acer rubrum L. and Acer pensylvanicum L.).

Herbivores did not change spatial patterns of maple regeneration, over either the short or the long term (but see McAuliffe, 1986; Ostfeld and Canham, 1993; García et al., 2000). Both inside and outside the experimental exclosures the lowest percentage of saplings appeared in open microsites, whereas the highest was associated with shrubs. This result suggests that the main factor affecting sapling distribution was not related to ungulates, but presumably to the modification of the abiotic environment by shrubs. In fact, the attenuation of extreme temperatures and radiation has been often highlighted as a main mechanism facilitating recruitment in stressprone ecosystems as the Mediterranean (Valiente-Banuet and Ezcurra, 1991; Callaway, 1992; Gómez et al., 2001b), where summer drought is a major factor limiting recruitment (Herrera et al., 1994; Rey and Alcántara, 
2000; García, 2001; Castro et al., 2004; Gómez, 2004). In agreement with this hypothesis, at all locations maple recruits occurred in shady microsites, mainly under shrubs but also under tree canopy and even stones, whereas the abundance of saplings living in full sunlight was consistently very low.

Although herbivores did not influence spatial patterns of maple recruitment, they had a considerable negative impact on sapling performance (see also Zamora et al., 2001). Growth rates were significantly slower for saplings outside the 20 year-old exclosure than for saplings inside. Consequently, the average height of maples in the absence of browsers was more than two times the height of maples accessible to ungulates, and even three times for saplings older than 16 years (131 versus $46 \mathrm{~cm}$ ). This significant effect on growth rates is related to the fact that taller, and therefore, older saplings are more heavily browsed than shorter ones (Crawley, 1997; Nomiya et al., 2003). Thus, saplings with the higher potential growth because their larger size are also the most intensively affected by herbivory. Furthermore, the usual consumption of the leader shoots causes a disruption of the apical dominance, resulting in cushion-shaped individuals (Miller and Cummins, 1982; Cuartas and García-González, 1992). Ungulates are, thus, a main factor limiting sapling growth throughout the maple distribution area, a situation that in turn could significantly affect population demographic structures.

\subsection{Effects of herbivores at the population level: uncou- pling age and size structures}

Ungulate herbivory had significant repercussions on age and size population structures. However, the effect was notable only when both structures were analysed together (Johnson and Fryer, 1989; Abrams et al., 1995; Zackrisson et al., 1995). Although age structures varied widely between populations, two main patterns were identified: populations represented mainly by young saplings (2-4 years), and mainly by adult and saplings in the larger age classes. On the other hand, most populations showed similar size structures, and 11 of the 16 populations studied followed an inverse J-shaped distribution characteristic of stable populations with sufficient regeneration (Leak, 1965; Hett and Loucks, 1976; Zackrisson et al., 1995; Poorter et al., 1996). As a result, when taking together age and size structure, we found that "old populations" (populations composed mainly of adult and saplings in the larger age classes) presented in many cases size structures similar to those of "young populations" (populations comprised mainly of young saplings), suggesting that maple saplings in population structures advance through age but not through height classes. In other words, maple saplings become older but not higher. Taking into account the severe effect of un- gulates on sapling growth rate, herbivory appears here to be the main factor responsible for the uncoupling of age and size structures. Thereby, the inverse J-shaped size structures found in most populations could not be interpreted as indicators of successful population regeneration, but the image of a bank of stunted saplings that will hardly grow into adults.

Over the long term, this collapse in the sapling-adult transition could diminish population size due to the lack of turnover of reproductive adults (Crawley, 1983; Zamora et al., 1999). If we consider $1.5-2 \mathrm{~m}$ as the threshold from which maples get into adult stage (authors's pers. obs.), the adult stock in the 16 populations studied would be very low. Contrary to other woody, remnant species inhabiting Mediterranean mountains, such as Juniperus communis (García et al., 1999) and Pinus sylvestris (Castro et al., 2004), maple recruitment would not collapse at the transition of seed-to-seedling stage because of summer drought, but rather later, in the sapling-to-adult transition because of herbivory.

\subsection{Ecological consequences for conservation and resto- ration}

According to demographic characteristics, maple populations in Mediterranean mountains show remnant dynamics (sensu Eriksson, 1996). Small fragments are locally maintained by the longevity of at least some reproductive adults, of even hundreds of years old. In the meantime, the large sapling bank presented in almost every population does not contribute to maintenance by regeneration, since a continuous disturbance such as herbivory prevent saplings from growing to maturity. In this situation, maple populations would be highly sensitive to episodic large-scale disturbances (such as fire or cutting) involving remnant seed sources (adults). Consequently, the conservation of $A$. opalus subsp. granatense populations in the long term is strongly dependent on the reduction of the herbivore pressure throughout the whole maple distribution area in the Iberian Peninsula. A few years without herbivory would represent the necessary "window of opportunity" (sensu Eriksson and Fröborg, 1996) for juvenile maples to grow enough to escape from chronic damage, finally entering the adult stock (Narjisse, 1998; Zamora et al., 2001). Since herbivory is a direct result of human intervention at the local scale, it could be easily controlled by temporal exclosures or livestock rotation. Additionally, restoration activities could be conducted in populations were size structures reveal a scarcity or lack of saplings in the lower age classes. Given that shrubs are the main regeneration niches, they should be used as transplanting microsites that facilitate the establishment of maple recruits (Gómez-Aparicio et al., 2004). 


\section{Acknowledgements}

We thank the Consejería de Medio Ambiente, Junta de Andalucía, for permission to conduct the field work in the Sierra Nevada National Park and in the Natural Parks of the Sierra de Baza, Sierra de Cazorla, Segura and las Villas, and Sierra de Alhama, Tejeda and Almijara. We are especially grateful to Pedro Jordano, Miguel Verdú, Gabriela Gleiser, and Patricio GarcíaFayos for their assistance in the location and sampling of maple populations. Sergio de Haro also supplied invaluable help in the field. David Nesbitt looked over the English version of the manuscript. This study was supported by a PFPU-MECD grant to L. Gómez-Aparicio and projects FEDER 1FD97-0743-CO3-02, REN 20014552-E and REN 2002-04041-CO2-01/GLO from MCYT.

\section{References}

Abrams, M.D., Orwing, D.A., Demeo, T.E., 1995. Dendroecologial analysis of successional dynamics for a pre-settlement-origin whitepine-mixed-oak forest in the southern Appalachian, USA. Journal of Ecology 83, 123-133.

Andrzejczyk, T., Brzeziecki, B., 1995. The structure and dynamics of old-growth Pinus sylvestris (L.) stands in the Wigry National Park, north-eastern Poland. Vegetatio 117, 81-94.

Bennett, K.D., Tzedakis, P.C., Willis, K.J., 1991. Quaternary refugia of north European trees. Journal of Biogeography 18, 103-105.

Blanca, G., Cueto, M., Martínez-Lirola, J., Molero-Mesa, J., 1998. Threatened vascular flora of Sierra Nevada (Southern Spain). Biological Conservation 85, 269-285.

Blanca, G., Cabezudo, B., Hernandez-Bermejo, J.E., Herrera, C.M., Muñoz, J., Valdés, B., 2000. Libro Rojo de Flora Amenazada de Andalucía. Consejería de Medio Ambiente, Junta de Andalucía, Sevilla.

Blondel, J., Aronson, J., 1999. Biology and Wildlife in the Mediterranean Region. Oxford University Press, Oxford.

Boerner, R.E.J., Brinkman, J.A., 1996. Ten years of tree seedling establishment and mortality in an Ohio deciduous forest complex. Bulletin of the Torrey Botanical Club 123, 309-317.

Buckley, D.S., Sharik, T.L., Isebrands, J.G., 1998. Regeneration of northern red oak: positive and negative effects of competitor removal. Ecology 79, 65-78.

Bullock, J., 1996. Plants. In: Sutherland, W.J. (Ed.), Ecological Census Techniques: a Handbook. Cambridge University Press, Cambridge, pp. 111-138.

Callaway, R.M., 1992. Effects of shrubs on recruitment of Quercus douglasii and Quercus lobata in California. Ecology 73, 2118-2128.

Callaway, R.M., 1995. Positive interactions among plants. The Botanical Review 61, 306-349.

Castro, J., Zamora, R., Hódar, J.A., Reyes, J.M., 2004. Seedling establishment of a boreal tree species (Pinus sylvestris ) at its southernmost distribution limit: consequences of being in a marginal Mediterranean area. Journal of Ecology 92, 266-277.

Clark, J.S., Beckage, B., Camill, P., Cleveland, B., HilleRisLambers, J., Lichter, J., McLachlan, J., Mohan, J., Wyckoff, P., 1999. Interpreting recruitment limitation in forests. American Journal of Botany $86,1-16$.

Condit, R., Sukumar, R., Hubbell, S.P., Foster, R.B., 1998. Predicting population trends from size distributions: a direct test in tropical tree communities. American Naturalist 152, 495-509.
Costa, M., Morla, C., Sainz, H. (Eds.), 1998. Los Bosques Ibéricos. Editorial Planeta, SA, Barcelona.

Cowling, R.M., Rundel, P.W., Lamont, B.B., Arroyo, M.K., Arianoutsou, M., 1996. Plant diversity in Mediterranean-climate regions. Trends in Ecology and Evolution 11, 362-366.

Crawley, M.J., 1983. Herbivory, the Dynamics of Animal-Plant Interactions. Blackwell Scientific Publications, Oxford.

Crawley, M.J., 1997. Plant-herbivore dynamics. In: Crawley, M.J. (Ed.), Plant Ecology, second ed. Blackwell Scientific Publications, Oxford, pp. 401-474.

Cuartas, P., García-González, R., 1992. Quercus ilex browse utilization by Caprini in Sierra de Cazorla and Segura (Spain). Vegetatio 99/100, 317-330.

Dubost, M., 1998. European policies in livestock grazing in Mediterranean ecosystems. In: Papanastasis, V.P., Peter, D. (Eds.), Ecological Basis of Livestock Grazing in Mediterranean Ecosystems. EUR 18308, Luxemburgo, pp. 298-311.

Eriksson, O., 1996. Regional dynamics of plants: a review of evidence for remnant, source-sink and metapopulations. Oikos 77, 248-258.

Eriksson, O., Fröborg, H., 1996. Windows of opportunity for recruitment in long-lived clonal plants: experimental studies of seedling establishment in Vaccinium shrubs. Canadian Journal of Botany 74, 1369-1374.

Font, I., 1983. Atlas Climático de España. Instituto Nacional de Meteorología, Cartografía Española, SA, Madrid.

García, D., 2001. Effects of seed dispersal on Juniperus communis recruitment on a Mediterranean mountain. Journal of Vegetation Science 12, 839-848.

García, D., Zamora, R., Hódar, J.A, Gómez, J.M., 1999. Age structure of Juniperus communis L. in the Iberian Peninsula: conservation of remnant populations in Mediterranean mountains. Biological Conservation 87, 215-220.

García, D., Zamora, R., Hódar, J.A, Gómez, J.M., Castro, J., 2000. Yew (Taxus baccata L.) regeneration is facilitated by fleshy-fruited shrubs in Mediterranean environments. Biological Conservation 95, 31-38.

Gómez, J.M., 2004. Importance of burial and microhabitat on Quercus ilex early recruitment: non-additive effects on multiple demographic processes. Plant Ecology (in press).

Gómez, J.M., Gómez, L., Zamora, R., Montes, J., 2001a. Problemas de regeneración de especies forestales autóctonas en el espacio natural protegido de Sierra Nevada. In: Anon. (Ed.), Montes para la sociedad de un nuevo milenio, vol. 6. Junta de Andalucía, Sevilla, pp. 212-218.

Gómez, L., Zamora, R., Hódar, J.A., Gómez, J.M., Castro, J., 2001 b. Facilitation of tree seedlings by shrubs in Sierra Nevada (SE Spain): disentangling the mechanisms. In: Radoglou, K. (Ed.), Forest Research: a Challenge for an Integrated European Approach. NAGREF, Forest Research Institute, Thessalonike, Greece, pp. 395-400.

Gómez-Aparicio, L., Zamora, R., Gomez, J.M., Hódar, J.A., Castro, J., Baraza, E., 2004. Applying plant facilitation to forest restoration in Mediterranean ecosystems: a meta-analysis of the use of shrubs as nurse plants. Ecological Applications (in press).

Gray, A.N., Spies, T.A., 1997. Microsite controls on tree seedling establishment in conifer forest canopy gaps. Ecology 78, 24582473.

Grove, A.T., Rackham, O., 2001. The Nature of Mediterranean Europe: an Ecological History. Yale University Press, London.

Herrera, C.M., Jordano, P., López-Soria, L., Amat, J.A., 1994. Recruitment of a mast-fruiting, bird-dispersed tree: bridging frugivore activity and seedling establishment. Ecological Monographs 64, 315-344.

Hett, J.M., Loucks, O.L., 1976. Age structure models of balsam fir and eastern hemlock. Journal of Ecology, 64,1682-1690.

Hódar, J.A., Castro, J., Gómez, J.M., García, D., Zamora, R., 1998. Effects of herbivory on growth and survival of seedlings and 
saplings of Pinus sylvestris nevadensis in SE Spain. In: Papanastasis, V.P., Peter, D. (Eds.), Ecological Basis of Livestock Grazing in Mediterranean Ecosystems. EUR 18308, Luxembourg, pp. 264 267.

IUCN, 2000. IUCN Red List Categories. IUCN, Gland.

Johnson, E.A., Fryer, G.I., 1989. Population dynamics in lodgepole pine-Engelmann spruce forests. Ecology 70, 1335-1345.

Leak, W.B., 1965. The J-shaped probability distribution. Forest Science 11, 405-409.

Leopold, A.C., Kriedemann, P.E., 1975. Plant Growth and Development, second ed. McGraw Hill, New York.

López-Gónzalez, G., 1994. La guía de Incafo de los árboles y arbustos de la Península Ibérica. Editorial Incafo, Madrid.

Lorimer, C.G., Chapman, J.W., Lambert, W.D., 1994. Tall understorey vegetation as a factor in the poor development of oak seedlings beneath mature stands. Journal of Ecology 82, 227-237.

McAuliffe, J.R., 1986. Herbivore-limited establishment of a Sonoran Desert tree, Cercidium microphyllum. Ecology 67, 276-280.

Miller, G.R., Cummins, R.P., 1982. Regeneration of Scots pine Pinus sylvestris at a natural tree-line in the Cairngorm Mountains, Scotland. Holarctic Ecology 5, 27-34.

Morrison, S.F., Forbes, G.J., Young, S.J., 2002. Browse occurrence, biomass, and use by white-tailed deer in a northern New Brunswick deer yard. Canadian Journal of Forest Research 32, 1518-1524.

Narjisse, H., 1998. Ecological health of Mediterranean rangelands: is grazing livestock the prominent driving force? In: Papanastasis, V.P., Peter, D. (Eds.), Ecological Basis of Livestock Grazing in Mediterranean Ecosystems. EUR 18308, Luxembourg, pp. 187297.

Nathan, R., Muller-Landau, H.C., 2000. Spatial patterns of seed dispersal, their determinants and consequences for recruitment. Trends in Ecology and Evolution 15, 278-285.

Nomiya, H., Suzuki, W., Kanazashi, T., Shibata, M., Tanaka, H., Nakashizuka, T., 2003. The response of forest floor vegetation and tree regeneration to deer exclusion and disturbance in a riparian deciduous forest, central Japan. Plant Ecology 164, 263-276.

Noy-Meir, I., Gutman, M., Kaplan, Y., 1989. Responses of Mediterranean grassland plants to grazing and protection. Journal of Ecology 77, 290-310.

Ogden, J., 1985. Past, present and future: studies on the population dynamics of some long-lived trees. In: White, J. (Ed.), Studies on Plant Demography. Academic Press, New York, pp. 3-16.

Ostfeld, R.S., Canham, C.D., 1993. Effects of meadow vole population-density on tree seedling survival in old fields. Ecology 74, 1792-1801.

Poorter, L., Bongers, F., van Rompaey, R.S.A.R., de Klerk, M., 1996. Regeneration of canopy tree species at five sites in West African moist forest. Forest Ecology and Management 84, 61-69.

Primack, R.B., 1995. A Primer of Conservation Biology. Sinauer Associates, Inc., Sunderland, MA.

Rabinowitz, D., Cairns, S., Dillon, T., 1986. Seven forms of rarity and their frequency in the flora of the British Isles. In: Soulé, M. (Ed.), Conservation Biology. The Science of Scarcity and Diversity. Sinauer Associates Inc., Sunderland, MA, pp. 182-204.
Rey, P.J., Alcántara, J.M., 2000. Recruitment dynamics of a fleshyfruited plant (Olea europaea): connecting patterns of seed dispersal to seedling establishment. Journal of Ecology 88, 622-633.

Rice, W.R., 1989. Analyzing tables of statistical tests. Evolution 43, 223-225.

Rooney, P.T., Waller, D.M., 1998. Local and regional variation in hemlock seedling establishment in forests of the upper Great lakes region, USA. Forest Ecology and Management 111, 211224.

Sano, J., 1997. Age and size distribution in a long-term forest dynamics. Forest Ecology and Management 92, 39-44.

SAS, 2002. SAS/STAT user's guide, Version 8.2. SAS Institute, Cary, North Carolina, USA.

Schemske, D.W., Husband, B.C., Ruckelshaus, M.H., Goodwillie, C., Parker, I.M., Bishop, J.G., 1994. Evaluating approaches to the conservation of rare and endangered plants. Ecology 75, 584-606.

Simard, M., Bergeron, Y., Sirois, L., 1998. Conifer seedling recruitment in a southeastern Canadian boreal forest: the importance of substrate. Journal of Vegetation Science 9, 575-582.

Smallidge, P.J., Leopold, D.J., 1994. Forest community composition and juvenile red spruce (Picea rubens) age-structure and growth patterns in an Adirondack watershed. Bulletin of the Torrey Botanical Club 121, 345-356.

Stokes, M.E., Davis, C.S., Koch, G.G., 1995. Categorical Data Analysis Using the SAS System. SAS Institute, Cary, North Carolina.

Taylor, K.M., Aarssen, L.W., 1989. Neighbor effects in mast year seedlings of Acer saccherum. American Journal of Botany 76, 546554.

Valiente-Banuet, A., Ezcurra, E., 1991. Shade as a cause of association between the cactus Neobuxbaumia tetetzo and the nurse plant Mimosa luisiana in the Tehuacán Valley, Mexico. Journal of Ecology 79, 961-971.

Vogel, J.C., Rumsey, F.J., Schneller, J.J., Barrett, J.A., Gibby, M., 1999. Where are the glacial refugia in Europe. Evidence from pteridophytes. Biological Journal of the Linnean Society 66, 23-37.

Winn, A., 1985. Effects of seed size and microsite on seedling emergence of Prunella vulgaris in four habitats. Journal of Ecology 73, 831-840.

Zackrisson, O., Nilsoon, M.C., Steijlen, I., Hörnberg, G., 1995. Regeneration pulses and climate-vegetation interactions in nonpyrogenic boreal Scots pine stands. Journal of Ecology 83, 469483.

Zamora, R., Hódar, J.A., Gómez, J.M., 1999. Plant-herbivore interaction: beyond a binary vision. In: Pugnaire, F.I., Valladares, F. (Eds.), Handbook of Functional Plant Ecology. Marcel-Dekker, New York, pp. 677-718.

Zamora, R., Gómez, J.M., Hódar, J.A., Castro, J., García, D., 2001. Effects of browsing by ungulates on seedling growth of Scots pine in a Mediterranean environment: consequences for forest regeneration. Forest Ecology and Management 144, 33-42.

Zar, J.H., 1996. Biostatistical Analysis, third ed. Prentice Hall, Englewood Cliffs, NJ. 